\title{
Determinants of Employee Engagement during COVID 19 Pandemic (Case of Sri Lanka Technological Campus)
}

\author{
H. M. S. Manjaree ${ }^{1}$, D. A. S. Perera ${ }^{2}$ \\ ${ }^{1,2}$ Faculty of Business Studies, Sri Lanka Technological Campus, Meepe, Padukka, Sri Lanka \\ DOI: https://dx.doi.org/10.47772/IJRISS.2021.57043
}

\begin{abstract}
One of the main changes to the education sector organizational context that took place with the advent of the COVID 19 pandemic is the change in work practices. Sri Lankan educational institutes shifted the normal work practices into work from home (WFH) practice. The human resource practitioners identified a challenge when measuring employee engagement in work from home setting. Even though employee engagement has been widely researched, only a few pieces of research can be found on employee engagement in work from home settings during the COVID 19 pandemic. The survey was done with the selected 150 employees, using Simple random sampling. The questionnaire survey was done through email. The collected data was analysed using SPSS and followed the descriptive and regression analysis. The study reveals that the most significant factor which positively impacts employee engagement in the work from home concept is Technological Readiness. The second most significant factor is Empowerment and it proves that the empowered employees are more engaged. In addition, employee engagement can be increased by enhancing Learning Support, Reward, Recognition, Organizational Procedure, Leadership, Job Security, Safety, and Trust. The Rewards and Recognition are identified as the least endowment in work from home setting. The higher the number of years of service period is revealed the higher employee engagement in the work from home concept. Therefore, the length of the service period is recognized as a moderating variable in the Aon Hewitt Employee Engagement model. Thus the organizational policies and investments to increase employee engagement should be executed based on eight determinants namely; Technological Readiness, Empowerment, Learning Support, Reward Recognition, Organizational Procedure, Leadership, Job Security - Safety and Trust.
\end{abstract}

Key Words: Employee Engagement, Work from Home, Empowerment, Technological Readiness, Educational Institutes

\section{INTRODUCTION}

$\mathrm{T}$ The COVID 19 pandemic has accelerated in terms of intensity and expanded its global reach. The full or partial lockdown measures in many countries are now affecting almost 2.7 billion workers, representing around $81 \%$ of the world's workforce. With the current situation, most businesses across a range of economic sectors face drastic losses. And also small enterprises are facing an immense threat in their operations and solvency. Millions of workers in the world are vulnerable to income losses and layoffs [13].
To mitigate the employment issues due to COVID 19, ILO has introduced a policy framework that consists of four key pillars to fight COVID-19 based on International Labour Standards.

1. Stimulating the economy and employment.

2. Supporting enterprises, jobs and incomes.

3. Protecting workers in the workplace.

4. Relying on social dialogue for solutions.

Many countries are adopting the ILO policy framework to reduce employment issues. As a result, it is observed that the current impact of the crisis on economic output from the education sector is low, where the education sector shares 5.3 $\%$ in global employment [12]. The reason is education sector adopts the $3^{\text {rd }}$ ILO policy of 'adapt work arrangement' by executing the work from home concept.

According to the Asia HR research team [2], the HR leaders' perspective on remote working or work from home is highly possible in this pandemic situation. Knowledge workers in educational institutes can work remotely during COVID 19 pandemic time. The challenge for the HR leaders is to measure their performances in terms of employee engagement in remote work settings

Another challenge of the work from home concept is how organizations achieve the Sustainable Development Goal (SDG) number eight. The SDG number eight promotes sustained economic growth, higher levels of productivity, and technological innovation. The goal is to achieve full and productive employment, and decent work, for all women and men by 2030. Technological innovations emerged due to the work from home concept. Still, there is a problem in terms of achieving full and productive employment. It is vital to study how to measure employee productivity in terms of employee engagement. We should find the best solution to increase employee engagement if there are any issues while achieving full and productive employment. When organizations consist of highly engaged employees, there are growths in customer satisfaction, profits, and employee productivity [1], [8].

It is evident that the work from home concept is welcomed by most organizations and it is important to measure employee engagement to increase the employee's productivity. There is a dearth of research on conceptualizing the determinants of employee engagement in work from home concept at higher 
educational institutes in Sri Lanka during challenging times as the COVID 19 pandemic

Therefore, the proposed study sets forth to examine the following research problem,

What are the determinants of employee engagement in the work from home concept at higher educational institutes in Sri Lanka during challenging times as the COVID 19 pandemic?

\section{A. Specific Questions and objectives}

The research questions of the study are,

1. What the current level of employee engagement in SLTC is?

2. What are the most significant factors that affect employee engagement in work from home in SLTC?

3. How do age and gender impact the relationship between selected factors and employee engagement in the work from home concept in SLTC?

The Objectives of the study are,

1. To examine the current level of employee engagement.

2. To examine the most significant factors that affect employee engagement in work from home.

3. To examine the moderating effect of age and gender.

\section{LITERATURE REVIEW}

Employee engagement is a matter of concern for leaders in organizations across the world. People are the only factor that cannot be reproduced or imitated by competitive organizations. It is considered the most valuable asset if managed and engaged properly. Therefore, employee engagement is considered the most powerful factor to measure a company's vigor [4].

Employee engagement is defined in many ways by different researchers. According to the results of Gallup's meta-analysis study by Harter, Schmidt and Hayes [9], the Employee engagement is an individual's involvement, satisfaction, and enthusiasm for work. They observed a correlation between overall satisfaction and employee engagement and both showed generalizability across companies in their correlation with customer satisfaction-loyalty, profitability, productivity, employee turnover and safety outcomes. The study suggests that business unit outcomes can be increased by increasing employee satisfaction.

According to Harter, Schmidt and Hayes [9], there are three types of people in an organization, namely engaged employees, not engaged employees, and actively disengaged employees. Engaged employees are builders who consistently strive to give excellence within their roles. Not engaged employees focus on the tasks assigned to them rather than the goals of the organization. They do what they are told to do. Actively disengaged employees are critical individuals who not only do not perform well but also demotivate the performer in the organization.
Perrin's biennial study defined Employee engagement as an emotional or rational duality of both 'the will' and 'the way' where employees need the will of mission, passion and pride as well they need the resources, support and tools as the way to accomplish their mission and passion [17].

Kahn's [14] Personal engagement theory states that employees engage at work physically, cognitively and emotionally only when they see meaning in their work, feel safe at work and have enough personal resources at work to carry out their tasks. Psychological meaningfulness in the job is defined to skill variety, task autonomy, role status, role influence, dignified work relations; psychological safety is linked to not facing any negative consequence to self-image, status, or career; and psychological availability is associated with a sense of having the necessary physical, emotional or psychological resource at work. Robinson, Perryman and Hayday [19] added their arguments to Khan's theory. Employee Engagement is a positive attitude that the employee holds towards the organization, but the degree of their engagement depends on the level of support they receive from the organization.

The Aon Hewitt's Say, Stay, Strive model explained Employee Engagement as the level of rational thought, emotions, behaviours, intentions invested by employees in the organization. Say, stay, strive model believes the employee to be engaged only when an employee speaks positively about the organization to co-workers, potential employees, and customers; sense strong belonging and desire to be part of the organization; and exert full effort in their job for the success of the organization [10].

The engagement drivers of this model are

- The company practices namely communication, customer focus, diversity and inclusion, enabling infrastructure, talent management practices and staffing.

- The basics namely benefits, job security, safety, work environment and work/life balance.

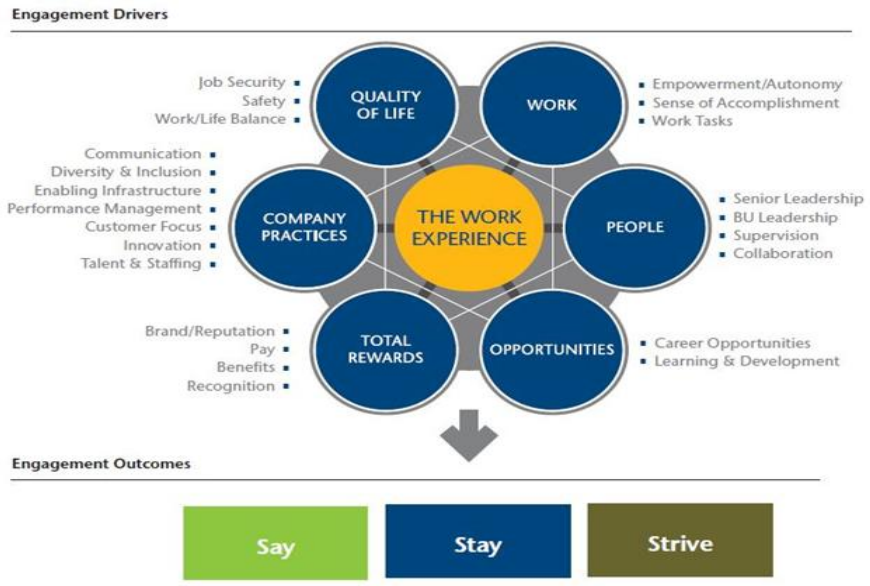

Fig. 1. Aon Hewitt Engagement Model

Source: Aon Hewitt [10] 
- The brand consists of reputation, employee value proposition and corporate responsibility.

- The leadership namely senior leadership and business unit leadership.

- The performance namely career opportunities, learning and development, performance management, people management, rewards and recognition.

- The work namely collaboration, empowerment, autonomy and work tasks

These drivers lead to business outcomes such as talent (retention, absenteeism, wellness), operational (productivity, safety), customer (satisfaction, net promoter score, retention), and financial (revenue/sales growth, operational income/margin, total shareholder return) [10]. Business outcomes link to the UN SGD 08, where the goal is reached through achieving higher levels of economic productivity through diversification, technological upgrading and innovation, including through a focus on high-value added and labour-intensive sectors. Further, gender and age are some of the noticeable factors when achieving productivity through decent work [18].

According to Aon Hewitt's model, the engaged employees exhibit the individual outcomes namely Say, Stay and Strive. As a result of Say, Stay and Strive behaviours, the organization will be benefited as below [10].

1. Increase the wellness, retention and talent thereby reduce absenteeism.

2. Therefore the safety and operational productivity increase.

3. If the internal customer is cared for by the company then the external customers will be taken care of by them. This results in retention of prospective customers, their satisfaction, and thereby, the net profits.

4. As a result of these, the revenues, operating income and shareholder's returns increases.

The Aon Hewitt's model was used for Employee engagement surveys which were done in 2015 and 2016, globally reaching 5 million employees across 60 plus industries. The results found $24 \%$ of employees were highly engaged and $39 \%$ of them were moderately engaged. Overall $63 \%$ of employees were found to be globally engaged in 2016 compared to $65 \%$ in 2015. The elements in the engagement index such as the Say component dropped from $69 \%$ to $68 \%$, Stay component from $60 \%$ to $59 \%$, and Strive component from $64 \%$ to $63 \%$. The study indicated that populist restrictions on the flow of labour between countries and major technology breakthroughs were the possible reasons for the decline in engagement [11].

\section{METHODOLOGY}

\section{A. Sample and Sampling Technique}

The simple random sampling technique identified 200 employees in Sri Lanka Technological Campus. The questionnaire was pre-tested with randomly selected 10 employees. The finalized questionnaire was administrated through e-mail between May and June 2020. The instructions for filling it were included in the email. Social desirability was prevented by ensuring the anonymity of the respondents [16]. At the deadline, a total of 150 respondents sent their responses. The response rate is $75 \%$.

\section{B. Conceptual Framework}

The conceptual framework was developed to test the hypothesis using quantitative data analysis. There are eight independent variables namely; Leadership, Company practices, Job Security - Safety, Empowerment, Rewards Recognition, Trust, Technological Readiness and Learning Support. The dependent variable is employee engagement in the work from home concept. Age and gender are the moderating variables. The questionnaire was developed based on the conceptual framework.

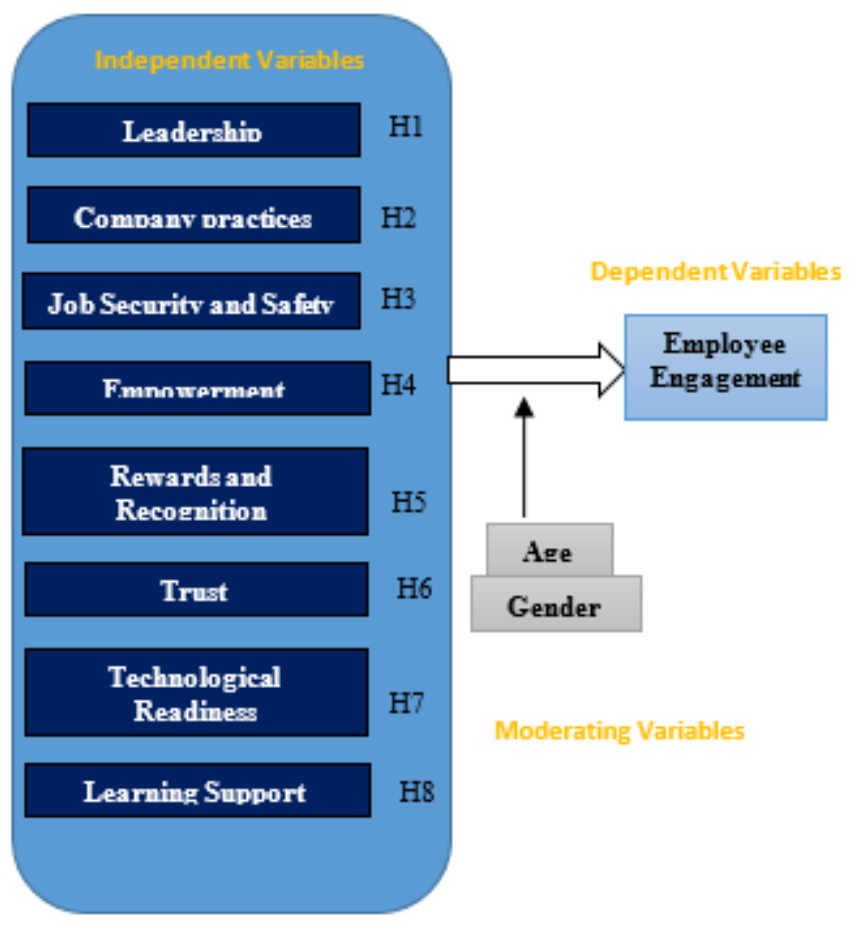

Fig. 2. Conceptual Framework

Adopted from Aon Hewitt Engagement Model

Sources: [10], [12]

Each respondent answered 54 questions. Each question was allocated to eight categories which are listed as independent variables in the conceptual framework. The next step consisted of analysis to identify additional factors that influence the engagement model when the respondent's age and gender are taken into consideration. Each respondent has to rate every question based on a seven-point scale ( $1=$ strongly disagree to 7 = Strongly Agree).

Descriptive analysis was done to find the first overview of data. Then detailed regression analysis was done using SPSS 
software which permitted to recognize of the influencing factors of the employee engagement in work from home.

\section{RESULTS AND DISCUSSION}

Out of 150 respondents, $59 \%$ were male employees and $41 \%$ were female employees. Around $30 \%$ of the respondents belonged to the age category of 26-30 \& 30-35. Only $23 \%$ of them were above 40 years of age. The respondents have different types of educational qualifications. Around $25 \%$ of them are PhD holders, $32 \%$ of them are Masters/ MPhil degree holders and $34 \%$ of them were with the highest qualification of a bachelor's degree.

Respondents belonged to two main work categories. The majority of them $(66 \%)$ belong to the Academic category and the rest of them are belong to the Non-Academic category. Around $25 \%$ of them were in the service with SLTC between $2-5$ years. $28 \%$ of them were less than one year of service.

Regression analysis was used to estimate the relationships between the dependent variable and independent variables. It was used to assess the strength of the relationship between variables and for developing the future relationship between them. As shown in Table I, the Adjusted R Square value of 0.689 indicates that $69 \%$ of the model fit is achieved in the relationship that was predicted in the model.

Table I Model Summary

\begin{tabular}{|c|c|c|c|c|}
\hline Model & $\mathrm{R}$ & R Square & $\begin{array}{c}\text { Adjusted R } \\
\text { Square }\end{array}$ & $\begin{array}{c}\text { Std. Error of the } \\
\text { Estimate }\end{array}$ \\
\hline 1 & 0.857 & 0.735 & 0.689 & 0.701 \\
\hline
\end{tabular}

a. Predictors: (Constant), Technological Readiness, Empowerment, Rewards and Recognition \& Trust, Learning Support, Leadership, Organizational Procedures, Job security and benefits

b. Dependent Variable: Employee Engagement

Table II, shows that the p-value is significant (0.000) and it explains that at least one of the independent variables namely, Technological Readiness, Empowerment, Rewards Recognition, Trust, Learning Support, Leadership, Organizational Procedures, Job security and safety predicts a significant relationship with the dependent variable employee engagement in work from home concept.

Table II Anova

\begin{tabular}{|c|c|c|c|c|c|c|}
\hline \multicolumn{2}{|c|}{ Model } & Sum of Squares & Df & $\begin{array}{c}\text { Mean } \\
\text { Square }\end{array}$ & F & Sig. \\
\hline \multirow{3}{*}{1} & Regression & 63.831 & 8 & 7.979 & 16.255 & .000 \\
\cline { 2 - 7 } & Residual & 23.071 & 47 & .491 & & \\
\cline { 2 - 7 } & Total & 86.902 & 55 & & & \\
\hline
\end{tabular}

a. Predictors: (Constant), Technological Readiness, Empowerment, Rewards and Recognition \& Trust, Learning Support, Leadership, Organizational Procedures, Job security and benefits

b. Dependent Variable: Employee Engagement
Coefficient table III, indicates that the p-value of Empowerment (0.05) and Technological Readiness (0.000) is less than 0.05 implying that these two variables are the most significant factors that have an impact on employee engagement in remote working practices. Based on the Beta values also evident that there is a positive relationship between Empowerment $(\mathrm{B}=.181)$, Technological Readiness (B.683) and Employee Engagement. However, it is the Technological Readiness of the institute that had the most significant impact on Employee Engagement as per the Beta value amongst the significant variable. All the other independent variables showed a positive relationship with employee engagement. Therefore, the hypothesis of 'there is a positive significant relationship between employee empowerment and employee engagement as well as a positive significant relationship between technological readiness and employee engagement in remote working practices' is accepted.

Table III Coefficient

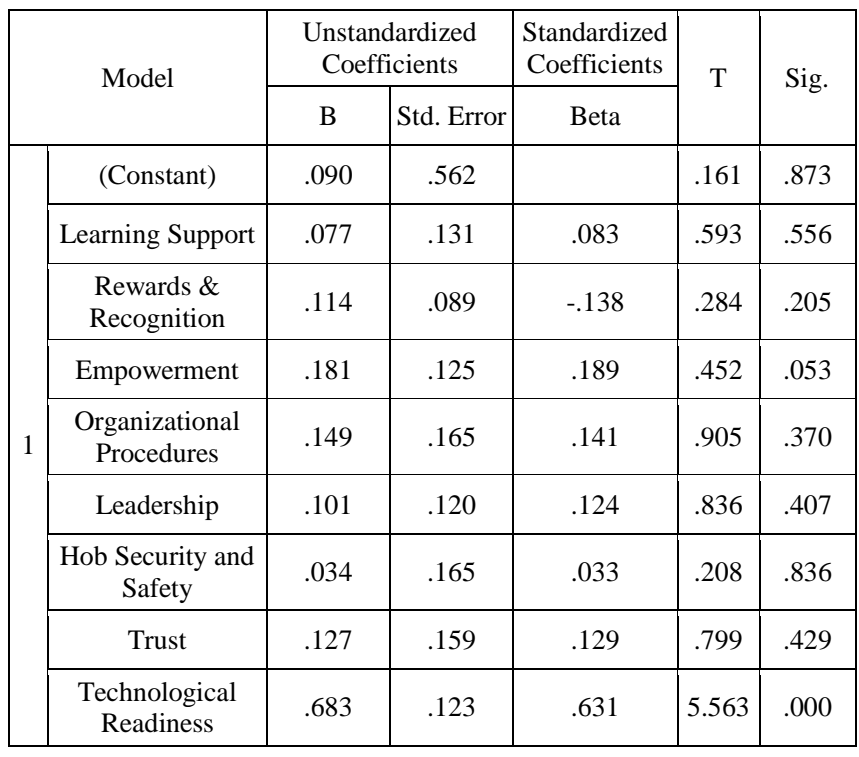

a. Dependent Variable: Employee Engagement

As per the ANOVA, there is a significant difference in the employee engagement in remote working practices compared to the length of service as the P-value is less than $0.05(0.19)$.

Table IV ANOVA Comparison of Means

\begin{tabular}{|c|c|c|}
\hline & & Sig. \\
\hline AVG Learning Support & Between Groups & .170 \\
\hline AVG R \& R & Between Groups & .764 \\
\hline AVG Empowerment & Between Groups & .332 \\
\hline AVG OP & Between Groups & .506 \\
\hline AVG Leader & Between Groups & .053 \\
\hline AVG JS & Between Groups & .424 \\
\hline AVG Trust & Between Groups & .703 \\
\hline
\end{tabular}




\begin{tabular}{|l|l|c|}
\hline AVG TR & Between Groups & .123 \\
\hline EE AVG & Between Groups & .019 \\
\hline
\end{tabular}

As per the descriptive table V, Employee engagement for employees who are with the organization for more than two years is high with a mean value of 6.2 compared to the ones who are less than 1 year or 6 months.

Table V Descriptive Compare Means

\begin{tabular}{|c|c|c|c|c|c|c|c|c|}
\hline & & \multirow{2}{*}{ Mean } & \multirow{2}{*}{$\begin{array}{c}\text { Std. } \\
\text { Deviation }\end{array}$} & \multirow{2}{*}{$\begin{array}{l}\text { Std. } \\
\text { Error }\end{array}$} & \multicolumn{2}{|c|}{$\begin{array}{l}95 \% \text { Confidence } \\
\text { Interval for Mean }\end{array}$} & \multirow{2}{*}{ Min. } & \multirow{2}{*}{ Max. } \\
\hline & & & & & $\begin{array}{l}\text { Lower } \\
\text { Bound }\end{array}$ & $\begin{array}{l}\text { Upper } \\
\text { Bound }\end{array}$ & & \\
\hline \multirow{6}{*}{ 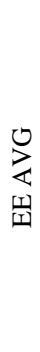 } & 1 & 4.71 & 2.138 & .713 & 3.07 & 6.35 & 1 & 7 \\
\hline & 2 & 5.94 & 1.035 & .259 & 5.39 & 6.49 & 4 & 7 \\
\hline & 3 & 6.23 & .814 & .332 & 5.38 & 7.09 & 5 & 7 \\
\hline & 4 & 6.20 & .823 & .220 & 5.72 & 6.68 & 4 & 7 \\
\hline & 5 & 6.42 & .678 & .204 & 5.96 & 6.87 & 5 & 7 \\
\hline & Total & 5.93 & 1.257 & . 168 & 5.60 & 6.27 & 1 & 7 \\
\hline
\end{tabular}

As per the overall mean values, respondents agree that their level of engagement during the remote working practices was high with a mean value of 6 . The order of importance of the other variables as per their level of agreement was Technological Readiness (5.8), Job Security and Safety (5.5), Empowerment (5.4), Trust (5.2), Learning Support (5.2), Leadership Support (5.2), well defined organizational procedures (5.23) \& Rewards and Recognition (4.2)

Table VI Overall Descriptive Values

\begin{tabular}{|c|c|c|}
\hline & Mean & Std. Deviation \\
\hline Learning Support & 5.2366 & 1.34538 \\
\hline Reward \& Recognition & 4.24 & 1.522 \\
\hline Empowerment & 5.39 & 1.313 \\
\hline Organizational Procedure & 5.23 & 1.186 \\
\hline Leadership & 5.21 & 1.546 \\
\hline Job Security and Safety & 5.46 & 1.217 \\
\hline Trust & 5.232 & 1.2757 \\
\hline Technological Readiness & 5.8795 & 1.16091 \\
\hline Employee Engagement & 5.93 & 1.257 \\
\hline Valid N (list wise) & & \\
\hline
\end{tabular}

The results prove that there is a positive relationship between all independent variables and employee engagement in the work from home concept. The most significant variable is technological readiness. In a work from home setting, employees have to use the Internet, e-mail, and electronic bulletin boards to perform their work. The majority of (66\%) the respondents belonged to academic category and they use Learning Management System (LMS) and Zoom online flat form to deliver online lectures. Non- academic staff also used Zoom online flat form for their meetings and Employee Management Information System (EMIS) to perform their duties during work from home period. Continuous training and helping sessions were conducted to improve their technological readiness.

The second most significant variable is Empowerment. Employees need the freedom to make decisions that relate to their job and they prefer freedom for their decisions of how to execute work. The findings prove Menon's [15] research findings again that the greater job autonomy and meaningfulness of the job lead to greater perceived control and greater empowerment. The findings explain the employees expect more job enrichment and job autonomy in work from home settings. Therefore, employee engagement can be increased by implementing job enrichment and job autonomy in work from home settings.

Results imply that employees need Job Security and Safety which has a positive relationship with employee engagement. If they have enough support to make them feel safe and free at all times during remote working periods, then their engagement is increased. Further, the employees expect Learning Support from the organization. The institute offered them opportunities to educate themselves and develop in their field of work even under Work from Home. COVID-19 pandemic created online learning opportunities for personal development and it saved employee's time to spend in such learning activities. Continues training and learning supports are mandatory for employees to improve their work engagements.

The outcomes indicate that trust is one of the noticeable factors which positively impact employee engagement. The administrators at all levels of the institute work to build shared ethical practice in work from home settings, but employees highlighted that building trust in a diversified organization is very difficult. The SLTC employees have a moderate trust with the organization in work from home setting. Further, the findings explain that constructive and well-informed organizational policies and procedures are essential to increase their engagement. Because employees can know any changes in policies and procedures which are related to the work from home concept.

Leadership is another variable that has a positive relationship with employee engagement. The organizations which indicated a high level of employee engagement are due to the leaders who execute the best strategies to enhance the level of employee engagement [5]. Their strategies cause a reduction in the levels of employee accidents and turnovers [3]. The findings of the study indicated the leader's vision, ideas and values with a focus on adaptability to the circumstances is an important and positive impact factor for employee engagement. And it should go beyond self-interest for the 
sustainable development of the institute especially during the work from home concept.

The employee's service period has a positive relationship with employee engagement. The findings indicate that there is a high employee engagement in work from home concept of employee those who have more than two years of the service period. There is a low level of employee engagement of the employees who have less than one year of the service period.

\section{RECOMMENDATIONS}

The findings of the study provide few recommendations for the organizations especially for educational institutes that adopt the work from home concept.

It is recommended to enhance the mechanism to empower employees with empowerment grids and monitoring and evaluations tools for the advancement of employee engagement in remote working practices in the higher education industry.

The Organization must invest in technological advancements and clearly defined technological infrastructure to improve the process efficiencies and delivery of the academics and nonacademics work in a remote working culture to develop employee engagement. The educational institutes can use Learning Management Systems and Employee Management Systems, which are compatible to appraise their KPIs. organizations should use the most appropriate virtual platforms, which answers the questions such as; how to form virtual a team, how to construct trust and motivation among employees who are not physically present, how to handle introverts, how to provide feedback, and how to deal with language issues [6].

The next recommendation is to build an organizational culture that values trust and provides continuous learning and development support. According to Chatman and Cha [7], social tools and training were identified as one of the tools to manage and change their culture for better performance in an organization.

\section{CONCLUSION}

The study proves that enhancing employee engagement is complex in an educational institute and there is not only one influencing variable. The most significant factor which positively impacts employee engagement in the work from home concept is Technological Readiness. The second most significant factor is Empowerment, where more empowered employees are more engaged. High employee engagement can be expected by increasing Learning Support, Reward Recognition, Organizational Procedure, Leadership, Job Security - Safety and Trust as well. The employees always concern about Rewards and Recognition, as it is somewhat less in work from home setting. Further, the length of service period is recognized as a moderating variable in Aon Hewitt Employee Engagement model. The higher the number of service periods is shown the higher employee engagement in the work from home concept.

\section{REFERENCES}

[1] Ahmetoglu, G., Harding, X., Akhtar, R., \& Chamorro-Premuzic, T. (2015). Predictors of creative achievement: Assessing the impact of entrepreneurial potential, perfectionism, and employee engagement. Creativity Research Journal, 27(2), 198-205. http://dx.doi.org/10.1080/10400419.2015.1030293

[2] Asia HR Research Team. (2020). ttps://www.gartner.com/ en/documents/3982100/2020-hr-leaders-priorities-andchallengesin-asia

[3] Barrick, M. R., Thurgood, G. R., Smith, T. A., \& Courtright, S. H. (2014). Collective organizational engagement: Linking motivational antecedents, strategic implementation, and firm performance. Academy of Management Journal, 58, 111-135. https://doi:10.5465/amj.2013.0227

[4] Baumruk, R. (2004). The missing link: The role of employee engagement in business success. Workspan, 47(11), 48-52.

[5] Blattner, J., \& Walter, T. J. (2015). Creating and sustaining a highly engaged company culture in a multigenerational workplace. Strategic HR Review, (14), 124-130. https://doi:10.1108/shr-062015-0043

[6] Cascio, W. F., \& Montealegre, R. (2016). How Technology Is Changing Work and Organizations. Annual Review of Organizational Psychology and Organizational Behavior, 349375. https://doi:10.1146/annurev-orgpsych-041015-062352

[7] Chatman, J., \& Cha, S.E. (2003). Leading by Leveraging Culture. California Management Review, 45, 20 - 34.

[8] Cooper-Thomas, H. D., Paterson, N. L., Stadler, M. J., \& Saks, A. M. (2014). The relative importance of proactive behaviors and outcomes for predicting newcomer learning, well-being, and work engagement. Journal of Vocational Behavior, 84(3), 318-331. http://dx.doi.org/10.1016/j.jvb.2014.02.007

[9] Harter, J.K, Schmidt, F.L \& Hayes, T.L. (2002). Business-unitlevel relationship between employee satisfaction, employee engagement, and business outcomes: A meta-analysis. Journal of Applied Psychology, 87(2), 268-279. http://dx.doi.org/10.1037//0021-9010.87.2.268

[10] Hewitt, A. (2015). Aon Hewitt's Model of Employee Engagement. Risk. Reinsurance. Human Resources.

[11] Hewitt, A. (2017). 2017 Trends in Global Employee Engagement, Global anxiety erodes employee engagement gains. Risk. Reinsurance. Human Resources.

[12] International Labour Organization. (2019). Global estimates for 2020 prior to COVID-19. . Geneva: International Labour Office.

[13] International Labour Organization. (2020). World Employment and Social Outlook- Trends 2020. Geneva: International Labour Office.

[14] Kahn, W.A. (1990). Psychological conditions of personal engagement and disengagement at work. Academy of Management Journal, 33(4), 692-724.

[15] Menon, S. T. (1995). Employee Empowerment: Definition, Measurement and Construct Validation. Canada: McGill University.

[16] Nederhof, A.J. (1985). Methods of coping with social desirability bias: A review. European Journal of Social Psychology. https://doi.org/10.1002/ejsp.2420150303

[17] Perrin, T. (2003). Working today: Understanding what drives employee engagement 2003, Towers Perrin Talent Report. Stamford, CT: Towers Perrin.

[18] Ritchie, S. J, Cox, S. R, Shen, X, Lombardo, M .V, Reus, L.M, Alloza, C, Harris, M. A, Alderson, H. L, Hunter, S, Neilson, E, Liewald, D. C. M, Auyeung, B, Whalley, H .C, Lawrie, S. M, Gale, C. R, Bastin, M. E, McIntosh, A. M, \& Deary, I. J. (2018). Sex Differences in the Adult Human Brain: Evidence from 5216 UK Biobank Participants. Cerebral Cortex, 28(8), 2959-2975. https://doi.org/10.1093/cercor/bhy109

[19] Robinson, D., Perryman, S., \& Hayday, S. (2004, April). The Drivers of Employee Engagement. Report 408. Institute for Employment Studies, Mantell Building Falmer, Brighton BN1 9RF, UK 